\section{STUDY OF 50 CASES OF ACUTE LEUKAEMIA IN CHILDHOOD}

BY

R. B. THOMPSON, M.D., F.R.C.P.

AND

W. WALKER, M.D.

From the Royal Victoria Infirmary. Newcastle upon Tyne

During the past 10 years or so the problem of malignant disease in childhood - particularly acute leukaemia - has assumed a much greater importance than hitherto. This has certainly been due in part to the decline in morbidity and mortality from infectious diseases, but interest in acute leukaemia has during the same period been stimulated by the advent of certain therapeutic agents and by the hope that more potent and permanent remedies may soon be discovered. It is hoped that the present study may add something to our knowledge of the course and management of the disease and of the remedies now available.

\section{Material}

This is a study of 50 consecutive cases of acute leukaemia admitted to the Department of Child Health, Newcastle upon Tyne, during 1953-60. Only those patients are included who have died and whom it has been possible to observe during most of their illness : many others were seen for short periods or were referred for opinion only.

The youngest patient-a case of congenital leukaemia - was 5 weeks old at the time of diagnosis, and the upper limit of the series was fixed at 14 years of age. Between these extremes the age distribution is as given in Fig. 1. This shows the peak at ages 2 to 4 , which is

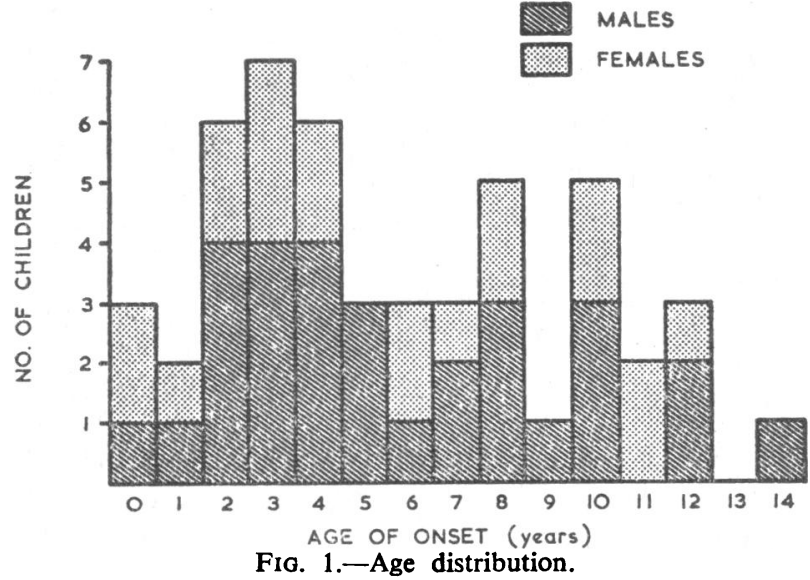

a feature of childhood leukaemia in Britain and in the white population of the United States (Cooke, 1942; Hewitt, 1955 ; Court Brown and Doll, 1961). The same figure shows the sex incidence ; there was the usual male predominance -30 males to 20 females.

The duration of the illness before diagnosis was often very difficult to ascertain. Sometimes, for instance, it was stated that the child had not been really well for two to three months since a respiratory illness. Even though there was a history of a recent decline in well-being which could be interpreted as the onset of leukaemia, suspicion often arose that the longer history was more likely to be correct. In many children, however, there was a very clear story of a sudden onset after a long period of normal health. The average estimated length of history was just under six weeks ; in five cases it was a week or less and in a further five cases it was over three months-two of these had histories of five to six months.

The principal presenting symptoms are shown in Table I.

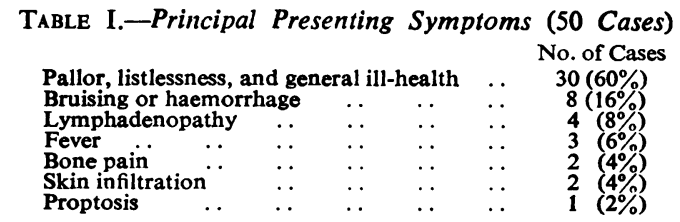

\section{Clinical Findings}

The frequency of anaemia is apparent from Fig. 2. In only one patient was the initial haemoglobin normal ; the presenting symptom was local leukaemic infiltration of the skin.

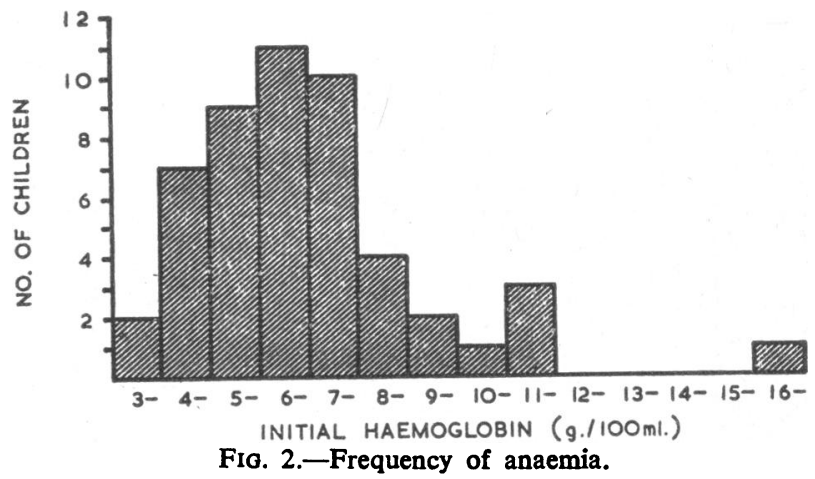

Skin haemorrhages were very commonly found at the initial examination. In $38 \%$ of the patients they were severe, there being marked generalized petechial rashes and extensive multiple bruises. In 36\% they were classified as mild, there being either localized petechiae or a few small bruises. No haemorrhagic tendency was apparent in the remaining $26 \%$. Two patients presented with recurrent rectal bleeding and in another there had been excessive bleeding after a dental extraction. Retinal haemorrhages were very common.

Lymph-node enlargement was generalized in over two-thirds of the children, but was usually moderate in degree. In a few children the enlargement was limited to the cervical region, and one had an isolated mass of axillary nodes. In only nine patients was there no significant node enlargement.

Splenic enlargement of up to $4 \mathrm{~cm}$. below the costal margin was present in three-quarters of the patients and only rarely was it greater than this. The organ could not be palpated in only six of the children.

The liver edge was palpable in all but eight patients ; enlargement of more than $4 \mathrm{~cm}$. was unusual.

Fever was present in $86 \%$ of the cases, although in only three was it a presenting symptom specifically mentioned by the parents. It usually subsided quickly on treatment with steroids and antibiotics. In many cases it was undoubtedly due to infective complications, but the precise cause was often uncertain.

No children presented with neurological signs and only one had proptosis. The cerebral complications which occurred during therapy are mentioned below. 
In two children skin infiltration was the first evidence of leukaemia. In one, a boy of $4 \frac{1}{2}$ years, there developed a dusky red thickening in the skin of one cheek where he had been bitten by a little girl a month before. When seen in hospital he had a similar lesion on one leg; biopsy of this showed leukaemic infiltration. This diagnosis was later confirmed by marrow aspiration, the peripheral blood findings being normal at the time. The second patient, a girl of 2 years, had a six-months history of a dusky brown swelling on the front of the left tibia. Two months before admission multiple swellings appeared over the chest wall. There was a periosteal reaction over both tibiae, one fibula, and one femur. Haematological investigation showed her to be suffering from acute lymphoblastic leukaemia. A third patient, a boy of 1 year, presented with two rounded scalp swellings associated with posterior auricular lymphadenopathy.

A fourth child was seen five weeks after birth with multiple bluish-purple rounded swellings in the skin. These were mostly 0.5 to $1 \mathrm{~cm}$. in diameter, but a few were up to $5 \mathrm{~cm}$. A similar lesion, thought at the time to be a bruise, had been present on the thigh since birth. There was gross hepatosplenomegaly and generalized lymphadenopathy. The initial white-cell count was $160,000 / \mathrm{c} . \mathrm{mm}$., most of which were blast cells of the granulocytic series. She died after nine days, and necropsy showed diffuse leukaemic infiltration of all organs and tissues.

Massive enlargement of the thymus was the most prominent presenting feature in a boy of 7 years. The remarkable resolution which followed steroid therapy is shown in Fig. 3.
The patient with a high haemoglobin level was of some interest, for he had at the time skin infiltrations only.

The initial leucocyte counts varied greatly from a marked leucopenia to a gross leucocytosis; they have been grouped in Table II. With two exceptions the platelet counts were all under $150,000 / \mathrm{c} . \mathrm{mm}$. and in nearly three-quarters of the cases they were under $50,000 / \mathrm{c} . \mathrm{mm}$. (Table III).

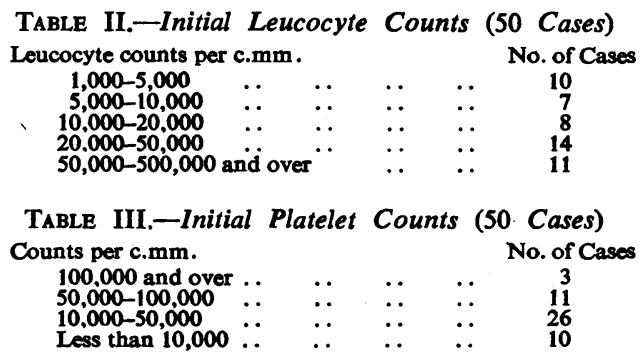

In those cases with high initial leucocyte counts the diagnosis was usually made on the appearance of the peripheral blood only. If, howeyer, there was any doubt, or if the leucocyte count was low, marrow aspirations were done. When the diagnosis was settled it was not usual to do repeated marrow examinations ; these were regarded as neither desirable nor necessary, for relapses were assessed on clinical grounds and by examination of the peripheral blood alone.

\section{Classification and General Management}

In all cases an attempt was made to classify the type of leukaemia. In $64 \%$ the predominant cells fulfilled the usually accepted criteria for acute lymphoblastic leukaemia. In $12 \%$ the cell type was quite uncertain, the blast cells appearing extremely primitive and showing no evidence of maturation into either cell series. In $22 \%$ many of the primitive blast cells showed, in Romanowsky-stained preparations, granulation typical of the myeloid series, and these cases were classified as acute myeloid leukaemia. In only one case were the cells typical of acute monocytic leukaemia; $t h$ is patient presented with a gross leucopenia and a hypocellular marrow, and the true diagnosis was for some time in doubt.

As soon as the diagnosis was clearly established one or both parents were told of the nature of their child's illness and their questions were answered as forthrightly as was thought justifiable. Many parents already suspected the truth, and to them confirmation was given as tactfully as possible. Some parents did not appear to realize, or would not bring themselves to accept, the gravity of the illness, and to them the truth had to be told more gradually. Some idea was given of the results to be expected from treatment, it being clearly indicated that remissions could only be temporary. Only after the parents' consent had been obtained was treatment started.
The initial haemoglobin levels (Fig. 2) clearly show the frequency of severe anaemia at the time of diagnosis. 


\section{Treatment}

Ten children were not treated-three were mongols and two were young babies; three were in a terminal state and died very quickly after admission; and in the other two cases the parents declined treatment.

Of the 40 treated patients most were given initial antibiotic cover, and because of the severity of the anaemia 25 children were transfused within the first few days of admission. Any influence this may have had on the subsequent remissions cannot be assessed. In 21 children one or more transfusions were necessary during the course of treatment; they were most frequently needed in those patients who failed to respond to therapy, and were given in the hope that perhaps a delayed response might occur. In the terminal illness, when it was clear that resistance had occurred to steroids and to antimetabolites, transfusions were sometimes given, but persistent transfusion at this stage was not practised.

\section{Steroid Therapy}

Steroid therapy was the initial treatment in most of the children; the rapidity of its effects and the improvement in general well-being was a great advantage. The earlier cases were all given cortisone and the later ones were treated with prednisone. The initial dosage of cortisone was usually 150 to $200 \mathrm{mg}$. and of prednisone $40 \mathrm{mg}$. daily whatever the age of the child. When it was apparent that a remission was established the steroids were gradually tailed off over some three to six weeks, during which time an antimetabolite-usually 6-mercaptopurine-was substituted. Of the 40 treated patients, 35 had initial ste:oid therapy: 22 were given cortisone and 13 prednisone. Full remission followed in 21 patients $(60 \%$ of those treated) and partial remissions occurred in a further six, giving an overall remission rate of $77 \%$. Of the eight failures, one child with acute lymphoblastic leukaemia died on the second day of uncontrollable bleeding; four children with acute lymphoblastic leukaemia survived long enough for assessment but showed no evidence of a response, and three had undoubted acute myeloid leukaemia.

The early withdrawal of steroids was intended to avoid the development of resistance so that they could be used again later in the course of the disease to cover a change of antimetabolite. It was often very advantageous to be able to use steroids in the terminal illness when resistance to both 6-mercaptopurine and folic-acid antagonists had developed. Second steroid remissionspartial or total-were obtained in 14 children, and steroids were used in two others but the results cannot be assessed. Only seven failed to respond a second time. When used for a third or fourth time remissions were naturally less frequent and less prolonged, but worth-while effects were often obtainable in the terminal illness.

Apart from mild hypercortical effects complications of steroid therapy were not common. In only one child treated with cortisone was there oedema due to water and salt retention; this quickly subsided and did not recur. The parents often needed some reassurance about the time of steroid withdrawal, for they feared the consequent reduction in appetite might have some ominous significance.
Steroid responses were usually prompt and reductions of the leucocyte count to normal or subnormal values often occurred within 5 to 10 days. A rise of the total leucocyte count to about twice normal often followed; this was due to an outpouring of polymorphonuclears. About the same time the platelet count returned towards normal values and the haemoglobin soon returned to normal also. In several cases the platelet counts and haemoglobin levels rose above normal for a few weeks before subsiding to normal. The remarkable destruction of cells which may occur in the first few days of treatment causes an increase in uric-acid excretion (Sandberg et al., 1956; Greenbaum and Stone, 1959). It is important that an adequate fluid intake be given at this time, otherwise there may be a precipitation of uric acid in the renal tubules with consequent renal failure. This occurred in only one of the present series, but fortunately it was treated before there was complete anuria. This same patient developed a terminal massive leukaemic infiltration of both kidneys.

\section{Antimetabolite Therapy}

The preparation most commonly used after the establishment of a steroid remission was 6-mercaptopurine; because of the overlapping of the two forms of therapy it is not possible to assess the results. Nevertheless 17 children did remain in full remission for periods of from 2 to 25 months (mean 5 months) while on this drug. The dosage given was roughly 2.5 $\mathrm{mg} . / \mathrm{kg}$. $/ \mathrm{day}$, and most children were given $50 \mathrm{mg}$. daily ; none were given less than this and a few older patients were given 75 to $100 \mathrm{mg}$. daily for at least part of the course. In nine patients $(25 \%$ of those to whom it was given) it was apparently ineffective. No side-effects were seen.

Of the folic-acid antagonists both aminopterin and methotrexate (" amethopterin ") were used. The dosage had to be carefully adjusted in each case, for individual tolerance varied greatly. The usual dosage of aminopterin was 0.25 to $0.5 \mathrm{mg}$./day; the dosage of methotrexate was five times this. All parents were warned to stop the drug and report at once if there was any symptom such as oral ulceration, vomiting, or diarrhoea, and, fortunately, no serious side-effects were seen: alopecia did not occur. The commonest complication was oral ulceration, and the dosage often had to be reduced on account of it. Twenty patients were treated with folic-acid antagonists, but because of the practice of giving them after steroids or with steroid cover it is not possible to assess the remission rate. With about four exceptions, however, the results were not impressive. In some cases the treatment might have been pressed harder, but it was not felt justifiable to obtain a haematological remission at the cost of distressing toxic side-effects.

\section{Complications Arising During Treatment}

Intracranial complications occurred in four children, and a summary of them is given below.

Case 22.-Acute leukaemia of lymphoblastic type was diagnosed in this boy at the age of $2 \frac{1}{2}$ years. A prompt and full remission was obtained with cortisone and was maintained with 6-mercaptopurine and later with aminopterin for 13 months. While still in full haematological remission he developed headache, vomiting, drowsiness, and a left hemiparesis. The cerebrospinal fluid showed a 
protein of $65 \mathrm{mg} . / 100 \mathrm{ml}$. and 360 lymphocytes per c.mm. There was no increase of pressure and no papilloedema was seen. Spontaneous remission of all symptoms and signs occurred over some 10 days, but he then developed a pathological appetite and became a prodigious size. Although this was presumably due to a local hypothalamic lesion it never showed any evidence of extension during the next eight to nine months, during which he remained in remission.

Case 24.-This boy was found to have acute lymphoblastic leukaemia at the age of $2 \frac{1}{2}$ years. A prompt remission on cortisone therapy was well maintained with 6-mercaptopurine at a dose of $50 \mathrm{mg}$. daily. He remained in full clinical and haematological remission for over 20 months, then began to complain of occipital headache, which was worse in the mornings and was associated with vomiting. Early bilateral papilloedema and paresis of both sixth cranial nerves were present. Skull radiographs were normal. Cerebrospinal fluid obtained by ventricular tap contained $10 \mathrm{mg}$. of protein per $100 \mathrm{ml}$. and 4 lymphocytes per c.mm. A ventriculogram did not show any obstruction in the flow of cerebrospinal fluid or demonstrate any space-occupying lesion in the brain. Histological examination of a small piece of dura mater showed no abnormality and a brain biopsy showed no gross leukaemic deposit, but several small vessels in an otherwise normal cortex had a single rim of encircling lymphocyte-like cells, and a single larger vessel had a layer of similar cells four to six thick along one side. These were thought to be minor leukaemic infiltrations. Treatment with steroids was started, $40 \mathrm{mg}$. of prednisone being given daily for 10 days, after which it was tailed off, the total course being 30 days. Recovery was prompt and complete with resolution of the papilloedema and disappearance of the strabismus. The haematological and clinical remission continued for another four and a half months, when, on early signs of relapse, aminopterin was given with steroid cover. Death occurred five months later.

Case 44.-Acute lymphoblastic leukaemia was diagnosed in this boy at the age of $4 \frac{1}{2}$ years and a remission was well maintained with steroids, 6-mercaptopurine, and aminopterin for some 22 months. A relapse was then successfully treated with a third course of prednisone. Three months later, when apparently in full remission, he suddenly had a generalized epileptic attack. Bilateral papilloedema developed and there was a left extensor plantar response. The cerebrospinal fluid protein was $40 \mathrm{mg} . / 100 \mathrm{ml}$. and there was no pleocytosis. Although the haemoglobin level was normal at this time, there was a slight thrombocytopenia and a few blast cells were present in the peripheral blood. Deep $x$-ray therapy was given in four doses over seven days, the central dose to the cranium totalling $650 \mathrm{r}$. There was a prompt remission of the neurological signs and no further epileptic attacks occurred. He soon went into a relapse which could not be controlled, and he died a month later.

Case 45.-A boy of 4 years had been in almost continuous remission for over 12 months from acute lymphoblastic leukaemia when he developed headache, vomiting, and papilloedema. The cerebrospinal fluid was not examined. A skull radiograph was normal. He was treated at first with prednisone at a dose of $40 \mathrm{mg}$. daily, but as this did not bring about any improvement deep $x$-ray therapy was given, the central dose to the skull being $650 \mathrm{r}$ over five days. The headache disappeared after the third dose of $x$ rays, the papilloedema receded, and he remained well for a further three months; then headache, vomiting, and papilloedema recurred. Again the cerebral symptoms remitted after deep $x$-ray therapy to the skull, a total of $1,200 \mathrm{r}$ being given over eight days. He remained well for three months but then relapsed and died six weeks later.

In several other children focal leukaemic infiltrations occurred in other organs and tissues during the course of treatment. In one boy during an apparently full remission there occurred a severe swelling of one testis which reached a size of 3 to $4 \mathrm{~cm}$. This subsided on adding a short course of steroids to the antimetabolite he was having at the time ; it never, however, completely resolved. In only one case was there bilateral renal infiltration; this occurred late in the course of the disease and reached massive proportions. One child, a girl of 7 years, developed an isolated lymph-node enlargement in the neck which was proved by punch biopsy to be due to leukaemic infiltration. It responded well to local radiotherapy. One boy developed persistent and troublesome haematuria and renal pain; this was shown to be due to hydronephrosis. As he was in full remission from acute leukaemia the kidney was removed without complication and he remained in remission for over 18 months. In four cases bone pain occurred which proved very resistant to treatment. It was almost certainly due to leukaemic infiltration, but no radiological or other proof could be established.

\section{Cause of Death}

Because many of these children died at home it is not possible to say what was the precise cause of death. In many cases it seemed to be due to a combination of progressive anaemia which could not be controlled by transfusion, extensive leukaemic infiltration of vital organs, and infection. In some cases the history suggested that there had been cerebral haemorrhage. In one child who died of this cause the leucocyte count at the time of death was over $300,000 / \mathrm{c} . \mathrm{mm}$. and the haemorrhage had occurred into a focal cerebral infiltration. This was in contrast to the more usual diffuse petechial cerebral haemorrhage-often with subarachnoid bleeding-which is found in patients with lower cell counts and is probably mainly due to thrombocytopenia. This type of bleeding has been studied by Fritz et al. (1959).

\section{Discussion}

The use of the term "remission" is often rather uncertain. Remissions are only claimed here when there was a restoration of all haematological values to normal ; routine marrow punctures were not, however, carried out. Remission also implies a full restoration of the child to its previous state of health for at least a month; children of suitable age were able to attend school. On these criteria, only 24 full remissions can be claimed in the 40 children who were treated-a rate of $60 \%$. Taking the series as a whole, treated and untreated, the remission rate is $48 \%$. These figures do not compare very favourably with some which have been published. In some series, however, only cases of lymphoblastic leukaemia were included; if this is done with the present series the remission rate rises to $80 \%$, which is nearer the $94 \%$ claimed by Zuelzer and Flatz (1960). In the series of Lightwood et al. (1960), in which no differentiation was made according to type, $54 \%$ had one or more complete remissions lasting up to seven months ; if partial remissions are included $76 \%$ showed improvement.

Although a prolongation of survival time can often be achieved by treatment, and may indeed result from repeated transfusions alone, this does not mean that there has been a restoration to anything like normal health and well-being. Some of the children in the present series, though surviving for weeks or months, were not in full haematological remission, and existence was made a misery to them by repeated infections or by complications, such as bone pain, which were resistant to treatment. 
Of the 10 untreated patients-excluding one who survived for some two months - the survival time ranged from 4 to 20 days, with a mean of 12 days. The 40 treated patients survived from 2 days to 32 months, with a mean of 9.1 months. This figure compares unfavourably with that of Lightwood et al. (1960), whose cases had an average survival time of 13.3 months. His untreated cases, however, survived for three months, which would suggest that there was a higher proportion of very ill children in the present series. Zuelzer and Flatz (1960) also report a mean survival of 13 months in their cases of acute lymphoblastic leukaemia.

\section{Factors Influencing the Response}

In 12 children the predominant cell type was clearly granulocytic-this includes the case of monocytic leukaemia. Six of these cases were treated, but in only one was there a remission; this followed some 10 weeks of treatment with 6-mercaptopurine and multiple blood transfusions. When the remission became established treatment had been stopped because the outlook appeared hopeless. The mean survival time of the six cases was two months; one child survived for 90 days, but there was no clinical or haematological remission. Of the six undifferentiated cases only three were treated; in one there was a good remission with a 12-months survival; the other two did not respond, and died within two weeks.

Of the children thought to be suffering from acute lymphoblastic leukaemia-30 in all-the mean survival time was 11 months and there were full remissions in 24 patients $(80 \%)$. As the survival time of the whole series was 9.1 months, it would appear that the lymphoblastic cases did better. The chances of a worth-while remission would seem to be much poorer if the cell type is granulocytic. This conclusion was also reached by Fessas et al. (1954).

It has been suggested that there might be an inverse relationship between the initial leucocyte values and the prognosis (Haut et al., 1959 ; Zuelzer and Flatz, 1960). In the present series the survival time was approximately 20 weeks in those children with leucocyte counts of $5,000 / \mathrm{c} . \mathrm{mm}$. or less, whereas in those with counts of 5,000 to $50,000 /$ c.mm. the mean survival time was 43 weeks. This difference is highly significant $(\mathrm{P}<0.2>0.1)$. The eight children with leucocyte counts of over $50,000 /$ c.mm. survived a mean period of 31 weeks, but there was such a great individual variation in this small group that the significance cannot be assessed. This finding of a poorer prognosis in the leucopenic patients does not agree with the finding of the authors mentioned above.

There was no obvious relationship between prognosis and any other clinical or haematological finding.

\section{Summary}

A series of 50 cases of childhood leukaemia have been studied. Nearly all these children were treated initially with steroids, after which the antimetabolites 6-mercaptopurine and aminopterin or methotrexate were used successively after steroid withdrawal. Steroids were also used to cover changes of therapy and in the terminal illness. Of 10 untreated cases (excluding one which survived for two months) the mean survival time was 12 days. Of the 40 treated cases the overall survival time was 9.1 months. Cases of lymphoblastic leukaemia survived for 11 months, but with one doubtful exception no case of acute granulocytic leukaemia responded to treatment. Case summaries are given of four children who developed cerebral complications during treatment.

\section{REFERENCES}

Cooke, J. V. (1942). J. Amer. med. Ass., 119, 547.

Court Brown, W. M, and Doll, R. (196i) Brit, med. J., 1, 981. Fessas, P., Wintrobe, M. M., Thompson, R. B., and Cartwright, G. E. (1954). Arch. intern. Med., 94, 384

Fritz, R. D., Forkner, C. E., Freireich, E. J., Frei, E., and Thomas, L. B. (1959). New Engl. J. Med., 261, 59.

Greenbaum, D. and Stone, H. F. Hope (1959). Lancet, 1, 73.

Haut, A., Altman, S. J., Wintrobe, M. M., and Cartwright, G. E. (1959). Blood, 14, 828 .

Hewitt, D. (1955). Brit. J. prev. soc. Med., 9, 81.

Lightwood, R., Barrie, H., and Butler, N. (1960). Brit. med. J., 1, 747.

Sandberg, A. A., Cartwright, G. E., and Wintrobe, M. M. (1956). Blood 11,154

Zuelzer, W. W., and Flatz, G. (1960). Amer. J. Dis. Child., 100 , 886.

\section{ANAEMIA IN THE RETICULOSES}

\section{A. J. BOWDLER,* M.B., M.R.C.P.}

AND

\section{T. A. J. PRANKERD, M.D., M.R.C.P.}

Lymphoma Clinic, University College Hospital, and Medical Unit, University College Hospital Medical School, London

Among the diverse features of the reticuloses, one of the most constant is the appearance at some stage of anaemia, and in many patients there will be phases of the disease in which this is the principal cause of disability. The severity and rapidity of development of the anaemia is very variable, but, in general terms, a rapidly worsening anaemia, as in acute leukaemia, produces a much more profound disturbance and more marked symptoms than a slowly developing anaemia of similar degree. In chronic myeloid leukaemia the anaemia is early to develop but usually only very slowly progressive, so that patients may be found performing a normal range of daily tasks despite a well-marked reduction in their circulating haemoglobin level. In chronic lymphatic leukaemia, however, the anaemia is often delayed to a comparatively late stage of the disease and is more rapid in development once it has appeared, with the consequence that its effects are more insistent and its prognostic significance may be worse. The frequency with which anaemia is found in these conditions has been emphasized by studies such as those of Samuels and Bierman (1956), in which haemoglobin levels of under $10.3 \mathrm{~g} . / 100 \mathrm{ml}$. were demonstrated at some stage in $97 \%$ of cases of acute leukaemia, $95 \%$ of chronic myeloid leukaemia, and $75 \%$ of chronic lymphatic leukaemia.

Cure of these diseases remains unattainable, and their treatment is most often reduced to the management of their anaemia and the symptomatic treatment of lymphomatous masses. It is our purpose here to consider the former, which to us often appears to be a neglected aspect of these diseases.

\section{Investigation of Anaemia}

The cause of anaemia is only occasionally apparent in the individual patient, and the underlying processes are only now being defined with any certainty. 